\title{
CHANGING THE FOOD ENVIRONMENT Creating Vidant Health's Healthy Food Environment
}

\author{
Scottie Gaskins, MAEd; Kathryn Kolasa, PhD, RD, LDN; \\ Rose Ann Simmons, MPH; Njeri Njuguna, MS, RD, LDN; \\ Andy White, BS, AOS
}

\begin{abstract}
The Vidant Health Wellness team, registered dietitians, and food service operators have played a leadership role in defining healthy food environments for hospitals. Without the benefit of national guidelines, we responded to the call for a healthier eating environment in 2003, and it has evolved to meet the documented health needs of the employees and visitors of its entire health care system. Vidant Health has successfully implemented both environmental and policy changes. In 2012, Vidant Health adopted a corporate policy that requires $75 \%$ of the foods and beverages sold in hospital eateries and vending machines and $60 \%$ of items provided by caterers and/or purchased with Vidant Health funds meet healthy criteria, be labeled at the point of service, and be priced to encourage purchase. This policy retains customer choice compared with policies that ban food fryers, sugar-sweetened beverages, or other high calorie foods and beverages. Key words: calorie labeling, bealthy bospital eating environments, price leveraging
\end{abstract}

$\mathbf{L}$ ONG BEFORE the Institute of Medicine (IOM) released its report on solving the obesity epidemic in our nation, ${ }^{1}$ Vidant Medical Center followed by the Vidant Health made a concerted effort to increase access to healthier food and beverage options for all its employees and visitors. Vidant Health is a health care organization with more than 11000 employees who work in 10 hospitals, home health care, hospices, outpatient clinics, and wellness centers serving 29 counties of rural, eastern North Carolina. Vidant Health, in Greenville, North Carolina, is the tertiary care hospital and serves as the teach-

\footnotetext{
Autbor Affiliations: Vidant Health (Mss Gaskins and Simmons); Brody School of Medicine, East Carolina University (Dr Kolasa); and ARAMARK at Vidant Medical Center (Ms Njuguna and Mr White), Greenville, North Carolina.
}

The authors have nothing to disclose.

Correspondence: Kathryn M. Kolasa, PbD, ECU Family Medicine, 101 Heart Dr, Mailstop 654, Greenville, NC27834 (kolasaka@ecu.edu).

DOI: $10.1097 / T I N .0 b 013 e 31828 d 7 b e 5$ ing hospital for the Brody School of Medicine at East Carolina University. The 2012 IOM report stated that governments and decision makers in the business community/private sector should create food and beverage environments that reduce unhealthy food and beverage options while increasing healthier food and beverage options at affordable, competitive prices, following the theme "ensure that the healthy choice is the easy choice." There are no national standards that define healthier food environments or road maps to reach that goal. The Figure gives a timeline for Vidant Health efforts, which began in the 1980s but were pursued in earnest beginning in $2003 .^{2}$ The work, which has been termed "the Nutrition Initiative," has been guided by staff from Vidant Health System Employee Wellness committees and encouraged by top administrators.

Many groups, including the American Heart Association, ${ }^{3}$ the American Cancer Society, ${ }^{4}$ and the IOM, ${ }^{1}$ have called for the creation of environments that support individual efforts to achieve and maintain healthy weight. ${ }^{5}$ 


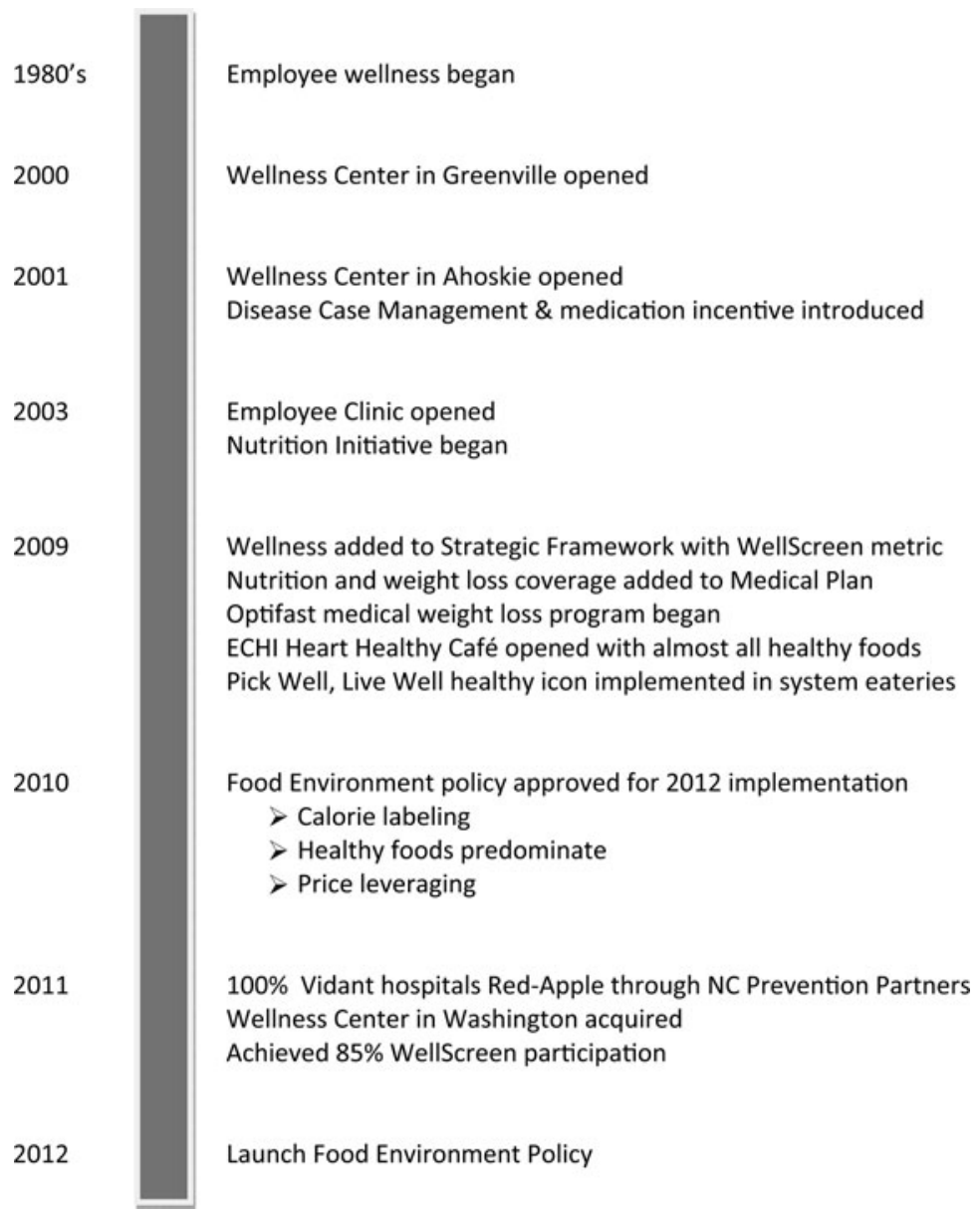

Figure. Historical timeline-Vidant Health Employee Wellness. ECHI indicates East Carolina Heart Institute.

Some hospitals have chosen to remove all fryers or eliminate all sugar-sweetened beverages or have meatless days. ${ }^{3,5,6}$ Vidant Health implemented additional strategies as a participant in NC Prevention Partners' (NCPP) 5step program to create healthy food environments in hospitals, ${ }^{7,8}$ and with no single path to creating a healthy food environment, challenges must be overcome each step of the way in a health system including, but not limited to, budgetary constraints, employee expectations, availability and accessibility of healthful food items, training of food service staff, and the variable food and nutrition knowledge of customers. Our journey is being shared to help others achieve an affordable, accessible, and healthy food environment that has the potential to impact the health of its regular customers. ${ }^{9}$

\section{HEALTHY DINING SINCE 2003}

The Vidant Medical Center had been a leader in creating a healthy food environment when it first joined the NCPP Winners Circle Healthy Dining Program in $2003 .{ }^{10} \mathrm{By}$ 2005, nutrition information was available in its main cafeteria at the point of purchase. A "healthy meal of the day" was featured and available during all shifts. In 2008, Vidant Health was among the first Centers of 
Excellence in the NCPP/North Carolina Hospital Association's healthy food environment program. ${ }^{8}$ A key player in helping shape this program, NCPP was awarded a Healthy Living Innovation Award from the United States Health and Human Services Secretary Kathleen Sebelius in 2011. The award was presented in recognition of cutting-edge work in health promotion that helped hospitals across North Carolina change the way they prepared, served, and marketed food to staff and visitors.

\section{THE EAST CAROLINA HEART INSTITUTE OPPORTUNITY}

While implementing the NCPP program in its main eateries and vending facilities, the opening of a café in a new heart hospital, the East Carolina Heart Institute (ECHI), provided another unique opportunity. The Nutrition Initiative studied the feasibility of creating a café that met the goals of the Dietary Guidelines for Americans, ${ }^{11}$ as well as science-based recommendations for heart healthy eating. The ECHI opened with a café promising that most $(80 \%)$ of the food and beverages served would meet heart healthy criteria. The only foods and beverages with nutrition labeling were those items that did not meet the criteria (eg, the California sushi roll carried a high sodium sticker). A committee that included registered dietitians (RDs) and food service professionals created the Guiding Principles for the ECHI eatery (Table 1). By 2009, the ECHI café and its vending service achieved the goal of providing a food environment where healthy was the norm rather than the exception.

There were obstacles (and continue to be) to maintaining this type of food environment. The obstacles included a lack of food products that qualify (especially for sodium); accurate ingredient measurements and consistent portion control; keeping customer interest; and financial management shared by the food service operator and a volunteer organization and distributing profits of the café to the hospital for needed programs, equipment, and services. The evidence to prove that these "costs" exceed the health "benefits" accrued to customers in these eateries did not exist. The Heart Cafe has remained a popular eatery and a nutrition education laboratory for employees, patients, and visitors.

\section{OPPORTUNITY FOR CHANGE}

To make the healthy choices easier, an icon called "Pick Well Live Well," selected by an employee vote, was used on menus and at point of service throughout Vidant Health starting in 2010. The icon identified foods meeting the NCPP healthy criteria (Table 2). ${ }^{8}$ All Vidant Health hospitals had earned "red-apple status" from the NCPP program by 2011 , meeting the 5 standards of (1) providing access to healthy foods; (2) adopting a pricing structure to incentivize customers to purchase healthy items; (3) marketing to promote healthy foods; (4) using wellness incentives to encourage behavioral change; and (5) implementing an education campaign to promote the healthy food environment with staff and visitors. ${ }^{8}$ While meeting NCPP standards, an audit revealed that less than $40 \%$ of foods and beverages sold on the medical center campuses could be considered "health promoting." Judging the environment insufficient to impact the high rates of employee obesity and chronic disease, additional changes to the food environment were warranted. In 2010, with $65 \%$ of all Vidant Health employees participating in a WellScreen conducted by the Occupational Health Department, 29\% were documented "overweight" and 44\% "obese" compared with national averages of $36 \%$ and $28 \%$, respectively, for the nation. At the same time, only $16 \%$ of Vidant Health employees were rated as having "poor nutrition," based on a self-report assessment included in the Health Risk Appraisal.

Faced with the alarming number that $73 \%$ of Vidant Health employees were overweight or obese, Vidant Health leadership agreed that more needed to be done to assist employees 
Table 1. Guiding Principles for Foods Offered at East Carolina Heart Institute, 2009

At the East Carolina Heart Institute, it will be the norm, not the exception, to find foods and beverages sold that will meet the heart healthy criteria.

$80 \%$ of the food and beverages sold will meet the heart health standards.

Foods that do not meet the criteria will carry a sticker indicating their exception. One example is a food labeled "higher sodium."

Items that are heart healthy are priced to encourage purchase.

Customers at the Heart Institute Café can be assured that the foods and beverages will generally fit into a heart healthy eating plan of 2000 cal per day.

The foods and beverages selected for service are:

Mindful of the need to limit calories, saturated fat, cholesterol, caffeine, and sodium.

No single dish or drink will have more $800 \mathrm{cal}$; meats will be lean; dairy products will be reduced fat.

A 6-oz main dish will have $<19.5 \mathrm{~g}$ of saturated fat; a 10 -oz product will have $<26 \mathrm{~g}$ of fat.

A 6-oz main dish will have $<6 \mathrm{~g}$ of saturated fat; a 10 -oz product will have $<8 \mathrm{~g}$ of saturated fat.

A 6-oz main dish will have $<90 \mathrm{mg}$ of cholesterol; a 10-oz product will have $<120 \mathrm{mg}$ of

cholesterol.

A 6-oz main dish will have $<720 \mathrm{mg}$ of sodium; a 10-oz product will have $<960 \mathrm{mg}$ of sodium.

Caffeinated beverages and foods will have no more than $15 \mathrm{mg}$ of caffeine per ounce.

Mindful to include food constituents that have positive benefits such as antioxidants, dietary fiber, omega-3 fatty acids, phytosterols, and monounsaturated fats and oils.

Fish served will be high in omega-3 fatty acids.

Vegetarian dishes will be available.

All breads and cereals will be whole grain; oat products will be offered.

Nuts will have $<4 \mathrm{~g}$ of saturated fat in $50 \mathrm{~g}(1.75 \mathrm{oz})$. These include walnuts, almonds, hazelnuts, peanuts, pecans, some pine nuts, and pistachios.

Seeds available include sesame, pumpkin, sunflower, and flaxseed.

Products with plant sterol esters, plant sterols, and/or enhanced with omega-3 fatty acids will be available.

Prepared in a heart healthy manner (eg, no deep, fat-fried foods; only use of canola, sunflower, or olive oil); herbs and spices rather than sodium.

The food and beverage selection has been reviewed by registered dietitians with additional expertise in cardiac wellness. Nutrition information is available for all foods and beverages sold upon request.

and visitors on all hospital campuses, clinics, and services in achieving and maintaining healthier weight status; a corporate policy should be drafted and adopted.

The development and implementation of a corporate healthy food environment policy were complicated by the reality that there were many different providers of food/vending services throughout Vidant. A few hospitals were self-operated cafeterias, and small, independent companies provided vending services. Others contracted with management companies or vendors such as ARAMARK, Morrison, SELECT Vending, and Canteen. Some of these vendors had their own healthy dining and/or labeling programs. On the basis of the evidence that reducing portion sizes (or downsizing) leads to reduced caloric consumption, ${ }^{12}$ the Nutrition Initiative Committee worked with all of the stakeholders to develop a policy focused on calories. A committee of Vidant Health RDs, in consultation with the food service operators throughout the Vidant Health, proposed the definitions for healthy foods (Table 3) and determined the percentage of menu items that could meet realistic calorie targets. While the Vidant Health policy focuses on calories, the RDs and wellness specialists asked that all involved support the spirit of the policy, which 
Table 2. Vidant Health Pick Well Live Well-Healthy Choice Criteria ${ }^{a}$

\section{Meal}

It is recommended that eateries provided at least one Pick Well Live Well meal choice at every dining shift.

Definition: The "Featured Meal of the Day" refers to a complete plate or combination of food offered for breakfast, lunch, or dinner. Typically, this includes a main dish and side item(s). To qualify, a "meal" must include 2 or more of the following:

- Fruit/vegetable

- Whole grain

- Lean protein (ie, skinless poultry, lean beef or pork, fish/seafood [includes salmon], tofu, beans/legumes, eggs, etc)

Calories: $<800$ per meal

Total fat: $\max 35 \%$ of calories

Saturated fat: $\max 10 \%$ of calories

Trans fats: $<0.5 \mathrm{~g}$ (negligible amount)

Sodium: $<1000 \mathrm{mg}$ per meal

Snacks

Every snack machine and the gift shop (where applicable) should have at least 1 (more would be preferable) snack item that meets the criteria that follows. That snack should be in the vending machine in a facing that is at eye level. The snack should not be priced higher than other snacks in the machine.

Items that are meal replacements (eg, sandwiches, meal replacements bars, shakes, and yogurt) are not included in this definition.

Definition: The "Snack" category refers to packaged or proportioned items such as pretzels, chips, crackers, cookies, yogurt, or quick breads/muffins.

A Pick Well Live Well snack is defined as per package:

Calories: $<200$

Sugar: $\max 35 \%$ calories from total sugars

Total fat: $\max 35 \%$ calories*

Saturated fat: $\max 10 \%$ calories

Trans fat: $<0.5 \mathrm{~g}$

Sodium: $<480 \mathrm{mg}$

* $100 \%$ nuts or seeds are exempt from the fat criteria

Beverages

Water should be available at every vending location and should not be priced higher than any of the other beverages vended at that place.

Considering sugar-sweetened beverages are a significant contributor to excess calories consumed, $50 \%$ of the beverages in a machine be "diet" or "reduced calorie. Recommend that both water and "diet" beverages be priced at a lower price than the full-calorie beverages.

Definition: The "Beverage" category refers to all beverages sold in hospital eateries, including vending machines and gift shops.

A Pick Well Live Well beverage is defined as:

- Diet soda

- Water and flavored water have $<50$ cal per 8-oz serving

- Unflavored skim, $1 \%$ or soy milk

. $100 \%$ real fruit juice: maximum serving size of $12 \mathrm{oz}$.

- Sports drinks be $<50$ cal per 8-oz serving

In addition, flavored coffees should have no more than 100 cal per 12-oz serving and have low- or no-fat additives available.

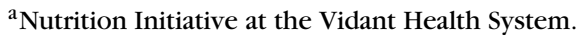


Table 3. Calorie Criteria for "Healthy" Items in the 2012 Vidant Healthy Food Environment Policy

\begin{tabular}{|ll|}
\hline Main dish & $<500 \mathrm{cal}$ \\
Side item & $<250 \mathrm{cal}$ \\
Meal & $<800 \mathrm{cal}$ \\
Soup $(8 \mathrm{oz})$ & $<225 \mathrm{cal}$ \\
Desserts/breads & $<200 \mathrm{cal}$ \\
Snacks & $<200 \mathrm{cal}$ \\
Condiments & $<75 \mathrm{cal}$ \\
Beverages & \\
$\quad \begin{array}{l}\text { Water, sports drinks, } \\
\text { diet sodas, juice drinks }\end{array}$ & $<50 \mathrm{cal} / 8 \mathrm{oz}$ \\
Milk and coffee drinks & $<100 \mathrm{cal} / 8 \mathrm{oz}$ \\
100\% juice & No cal limit; 12 \\
& $\mathrm{oz} \mathrm{max.}$ \\
\hline
\end{tabular}

is to provide fruits, vegetables, lean meats, and fish and to use food preparation techniques that maintain the healthfulness of the foods and beverages served.

The 4 key principles of the 2012 Healthy Food Environment Policy stipulate the following: (1) $75 \%$ of food and beverage options at onsite food venues meet healthy criteria; (2) $60 \%$ of food and beverages at company-sponsored events and celebrations meet healthy criteria; (3) healthy options are price-leveraged; and (4) all foods and beverages bear calorie labeling at the point of service.* Approved and endorsed by the Vidant Health administration, a lead time of 1 year was provided for the calorie-labeling provision and 2 years for full implementation in

\footnotetext{
*Note. Section 4205 of the Patient Protection and Affordable Care Act of 2010 requires restaurants and similar retail food establishments with 20 or more locations to list calorie content information for standard menu items on restaurant menus and menu boards, including drivethrough menu boards. Other nutrient information-total calories, fat, saturated fat, cholesterol, sodium, total carbohydrates, sugars, fiber, and total protein-are required to be available, in writing, upon request. The act also requires vending machine operators who own or operate 20 or more vending machines to disclose calorie content for certain items. ${ }^{13}$ Vidant was exempt from this regulation but chose to make the information available as a community role model for healthy eating.
}

every cafeteria, coffee shop, food cart, and vending machine in Vidant.

The implementation of the policy was overseen by a Steering Committee composed of a champion appointed by each Vidant Health hospital's president. This committee adjudicated unanticipated issues that emerged as the policy was implemented, developing definitions ${ }^{14}$ to support the policy. It also used a 90-day work plan scorecard to monitor compliance with the policy. Tactics included redesigning menus, finding and testing food products, modeling price-leveraging strategies to be "budget neutral," and preparing marketing and education materials. While there still were no "how-to manuals" available for creating a healthy food environment, the NCPP Work Healthy America program ${ }^{15}$ audit tools (available at: (http://www.ncpreventionpartners.org/dnn/ WorkHealthyAmerica/tabid/75/Default.aspx) and the Centers for Disease Control and Prevention's (CDC's) Healthy Hospital Practice to Practice Series ${ }^{16}$ provided some guidance.

The roll-out of the policy varied throughout the Vidant Health, depending on the available resources. Providing calorie labeling, applying the $75 \%$ rule, and price leveraging to vending products were the easiest to accomplish with all of Vidant Health hospitals in compliance within several months. Hospitals with food service management companies responded quickly to the implementation of the policy. Hospitals with self-operated cafeterias required more time and assistance to complete menu item analysis and meet the policy but typically surpassed the $75 \%$ rule in the end.

\section{IMPLEMENTATION FOR COMPANY-SPONSORED EVENTS}

An important feature of the 2012 Healthy Food Environment Policy is that it affected not only the food and beverages for sale in the Vidant Health but also the food and beverages purchased with company funds. At least $60 \%$ of food and beverages were required to meet the calorie goals. This policy 
affected everything from executive, staff, and Board lunches, to Continuing Medical Education programming, to the employee picnic, community fund-raising events, open houses, awards receptions, and meetings. To facilitate adoption, Tool Kits and webinar training were provided both for vendors and for event planners. ${ }^{14}$ Invitation letters were sent to all vendors who had supplied food or beverages to units in Vidant in the last year. As of fall 2012, all the Vidant Health food service operations and 14 other vendors that pledged to follow the policy are known as a "preferred vendor." (These toolkits are posted on the Vidant intranet and available online. ${ }^{14}$ ) Vendors have reported that they are using some of their new recipes and menus with other clients in the community.

\section{OUR EXPERIENCE IN MAKING HEALTHY AFFORDABLE}

Inspired by the success reported by First Health of the Carolinas ${ }^{17}$ in shifting employee purchases to healthier options through a pricing incentive without loss of revenue, a committee of Vidant finance officers developed a price-leveraging strategy to ensure that the healthy choice was the more affordable choice. Again, there were no road maps that made it easy to know what price differential will lead to a budget-neutral result, and there were not sufficient data to predict what size of price differential would be required to move customer behavior. The finance committee proposed a $25 \%$ price differential between healthy and less healthy "like" items as substantial enough to influence purchasing behaviors toward the healthier item. Each Vidant entity had created its own price-leveraging formula. For example, in the medical center's main cafeteria, a 3.5-oz oven-baked chicken breast $(165 \mathrm{cal})$ costs $\$ 1.83$ whereas a $3.5-\mathrm{oz}$ fried chicken breast $(270 \mathrm{cal})$ is $\$ 2.47$. During the first 7 months of this policy, the Vidant Medical Center reduced the price of its healthy entrée by $15 \%$ (from $\$ 2.99$ to $\$ 2.54$ ) and sales increased by an impressive $126 \%$. Sales for fish entrées have increased by $31 \%$.
The medical center increased the price of the nonhealthy entrée by $15 \%$ (from $\$ 2.99$ to \$3.44) and observed a decrease in sales of $30 \%$. It decreased the price of the salad bar by $19 \%$ (from 31 to 25 cents per ounce, with a $22 \%$ increase in sales). While the medical center gift shop was exempt from the policy, the volunteer organization operating it raised the price of candy and snack items that exceeded 200 calories. Some vending operations have reported a small decline in revenue from the previous year. It is not known at this time whether that decrease can be attributed to the implementation of the policy or is in response to other events occurring at the same time such as the poor economy, or the increased availability of healthy food options available to all shifts in the cafeterias, or worksite wellness promotions that included weight management and healthy snacking. A few of the Vidant Health entities were not able to meet the $25 \%$ differential, retain employee discounts, and achieve a budget-neutral outcome. Thus, additional data are needed at least over a 12month period to fully understand the trends and modify the policy if necessary to achieve increased sales of healthy items while meeting financial targets.

\section{NUTRITION EDUCATION CAMPAIGN HELPS CUSTOMERS USE HEALTHY FOOD ENVIRONMENT}

The Vidant Health Wellness programs provide healthy nutrition messages (Table 4). There is evidence that health promotion programs in the workplace are associated with reduced absenteeism, higher-quality performance and productivity, and lower health care costs. ${ }^{1}$ To ensure that the implementation of the 2012 Healthy Food Environment Policy impacts the overweight/obesity rates of Vidant Health employees, education about healthy eating is critical. A team of wellness specialists and RDs representing all Vidant Health hospitals planned a 20-month nutrition education campaign. The Vidant Health campaign of "Calories Count" is designed to 
Table 4. Nutrition Education Campaign

\begin{tabular}{|c|c|c|}
\hline Time & Topic & Sample Actions \\
\hline April-June 2012 & $\begin{array}{l}\text { Calories Count: How } \\
\text { Many Do You Need? }\end{array}$ & $\begin{array}{l}\text { 1. Distribute flyers with tear off tabs with site to learn: } \\
\text { www.caloriescount.com } \\
\text { Direct employees via Find it Fast to Vidant Wellness } \\
\text { website and Wellness App. } \\
\text { 2. Set up table in cafeteria and aid employees in } \\
\text { determining calorie needs with a prize drawing each } \\
\text { month from those who requested calorie needs by } \\
\text { the RD. }\end{array}$ \\
\hline July-Sept 2012 & Check the Facts & $\begin{array}{l}\text { 1. Distribute table tents showing how to read and and use } \\
\text { the info on food labels. } \\
\text { 2. Hold Crossword puzzle contest using Facts Labels } \\
\text { 3. Email blasts promoting label reading }\end{array}$ \\
\hline Oct-Dec 2012 & $\begin{array}{l}\text { Enjoy Your Food But } \\
\text { Eat Less }\end{array}$ & $\begin{array}{l}\text { 1. Introduce Supertracker site www.choosemyplate.com } \\
\text { Eat Less via email and posters to raise awareness of } \\
\text { portion sizes balance in the diet. } \\
\text { 2. Supply blank food journal sheets and instructions at } \\
\text { convenient facility locations to promote portion size } \\
\text { awareness. } \\
\text { 3. Showcase healthy portion sizes in cafeterias with labels } \\
\text { listing amounts of each food item. }\end{array}$ \\
\hline Jan-Mar 2013 & $\begin{array}{l}\text { Avoid Oversized } \\
\text { Portions }\end{array}$ & $\begin{array}{l}\text { 1. Emphasize food portioning by reading food labels and } \\
\text { measuring. Provide measuring demonstrations in the } \\
\text { cafeterias throughout the month. } \\
\text { 2. Refer employees to www.choosemyplate.gov for } \\
\text { portioning tips. } \\
\text { 3. Posters with lists of activity time needed to burn calories } \\
\text { of super-sized foods. }\end{array}$ \\
\hline April-June 2013 & $\begin{array}{l}\text { Drink Water Instead } \\
\text { of Sugary Drinks }\end{array}$ & $\begin{array}{l}\text { 1. Cafeteria display with interactive table with soda and } \\
\text { juice choices beside actual amounts of sugar. } \\
\text { 2. Table tents depicting beverage choices with calorie } \\
\text { listings and alternatives. } \\
\text { 3. Emails referring employees to www.extention.org for A } \\
\text { Day of Beverages. }\end{array}$ \\
\hline July-Sept 2013 & $\begin{array}{l}\text { Make Half Your Plate } \\
\text { Fruits and Vegetables }\end{array}$ & $\begin{array}{l}\text { 1. Hospital/departmental Lunch and Learns educating staff } \\
\text { about the health benefits of } 5+\text { fruits and vegetables a } \\
\text { day. } \\
\text { 2. Cafeteria taste tests of unique vegetable dishes. Aid } \\
\text { chef's in devising healthy vegetable and fruit recipes. } \\
\text { 3. Encourage fresh, locally grown in-season fruits and } \\
\text { vegetables via posters or flyers throughout hospital. }\end{array}$ \\
\hline Oct-Dec 2013 & $\begin{array}{l}\text { Switch to Skim or } \\
\text { Low-Fat Milk }\end{array}$ & $\begin{array}{l}\text { 1. Hold blind taste tests in cafeteria of skim, } 2 \% \text { and whole } \\
\text { milk. } \\
\text { 2. Refer to www.NationalDairyCouncil.org to download } \\
\text { kits on Lactose Intolerance and Dairy Is More Than Just } \\
\text { Milk. } \\
\text { 3. Cafeteria featuring healthy holiday desserts high In } \\
\text { calcium. } \\
\text { 4. Emails depicting the benefits and the nutritional quality } \\
\text { of milk and low fat dairy foods. }\end{array}$ \\
\hline
\end{tabular}


enhance the employees' ability and desire to use the calorie labeling in all food venues. A baseline measure describing Vidant Health employees' knowledge and attitudes toward calorie needs and labeling is not available. Anecdotally, we know from encounters at wellness events, including RDs staffing booths in the cafeteria offering calorie prescriptions, that many employees do not know their own daily caloric needs or how to use the calorie labeling now provided at point of service. Consistent with the literature on consumer understanding of caloric requirements, more education is needed if calorie labeling is to be an effective strategy in solving the obesity crisis. ${ }^{18,19}$

The Vidant Health has become a community partner in the US Department of Agriculture's effort to promote the Dietary Guidelines for Americans, and the corporate education campaign uses the resources and materials from the US Department of Agriculture campaign (http://www.choosemyplate.gov/ partnerships/communitypartnerslist.aspx).

Each Vidant Health hospital is taking leadership for the development of 1 message. And, while the message will be consistent throughout the Vidant Health, the events and implementation may vary by location. Every location has an electronic sign board and receives briefing messages from administrators and the employee newsletter that includes inspirational stories about employees who have successfully changed their lifestyle. Some locations will use Web sites with menus and nutrition information, table tents, posters, taste tests, and RD visits to the unit meetings. Communicating healthy eating and physical activity messages through Vidant Health's communication portals is challenging because these messages compete with other patient safety and quality messages.

\section{PROFESSIONAL SOCIETIES AND HEALTH AGENCIES}

In recent years, several organizations, including but not limited to the American Heart
Association, the American Cancer Society, and the CDC, have issued calls for increasing access to affordable, healthy foods in communities, worksites, and schools and decreasing access to foods and beverages of low nutritional value, particularly targeted to children and adolescents. They call for safe, enjoyable, and accessible environments for physical activity in schools and worksites and for transportation and recreation in communities.

An expert panel convened by the CDC concluded that the health section and public health have an opportunity to address the nation's chronic disease burden and health care costs by promoting healthy hospital food environments. $^{20}$ The panel suggested that healthy food be defined not only by nutrition standards but also by an economically and environmentally sustainable food system. It called for food policies to cover all venues, including cafeterias, vending machines, snack carts, and gift shops. This group also made an appeal for policy and environmental approaches to improve physical activity, breastfeeding, and tobacco-free environments in hospitals. In 2012, the CDC began working toward a national campaign for hospitals to build prevention into their strategic framework to support employee, patient, and community health.

The IOM's committee that developed the report Accelerating Progress in Obesity Prevention $^{1}$ was confident that if we have strategies that can solve the obesity crisis and encourages everyone to work together at the societal level, progress would be achieved. The Vidant Health has shown a commitment to working with others to solve this complex problem. Vidant has been successful in making environmental and policy changes that will support individuals and families in making healthy choices where they work, learn, eat, and play. Over the last 5 years, the employee obesity risk for overweight and obesity has slowly declined. It is not possible to delineate how much of the decline is due to the creation of a healthy food environment or to other efforts that assist employees in weight management (including providing 
employees with weight management visits to the RD as a medical benefit). It is known, however, that if employees who are overweight or obese or who have diabetes or cardiovascular risks cannot access healthy foods and beverages during their workday, they are unlikely to meet their own chronic disease selfmanagement goals. ${ }^{21}$ Tools and techniques for measuring the impact of policy and environmental change on the health outcomes of individuals are needed.

\section{SUMMARY}

The Vidant Health has evolved a healthy food environment over a period of 9 years, from starting with the offering of a few meal options that met heart healthy criteria ${ }^{10}$ to an environment that ensures that most foods and beverages offered or sold throughout the health care system are of appropriate calories per portion and priced advantageously. Support and encouragement from administrators were necessary to achieve key changes in the food environment. A corporate-wide policy ensures that individuals planning and serving foods and beverages, regardless of their operation or location, meet specific goals designed to lower the overweight/obesity rates among its employees and visitors. The Vidant Health has demonstrated that it can create a hospital environment where the healthy food or beverage is the easy choice while still retaining customer choice.

\section{REFERENCES}

1. Institute of Medicine. Accelerating Progress in Obesity Prevention: Solving the Weight of the Nation. Washington, DC: The National Academies Press; 2012. www.nap.edu. Accessed June 7, 2012.

2. Kolasa KM, Dial J, Gaskins S, et al. Moving toward healthier eating environments in hospitals. Nutr Today. 2010;45(2):54-63.

3. Gidding SS, Lichtenstein AH, Faith MS, et al. Implementing American Heart Association Pediatric and Adult Nutrition Guidelines: A scientific statement from the American Heart Association Nutrition Committee of the Council on Nutrition, Physical Activity and Metabolism, Council on Cardiovascular Disease in the Young, Council on Arteriosclerosis, Thrombosis and Vascular Biology, Council on Cardiovascular Nursing, Council on Epidemiology and Prevention and Council for High Blood Pressure Research. Circulation. 2009;119:1161-1175.

4. Kushi LH, Doyle C, McCullough M, et al. Nutrition and physical activity guidelines for cancer prevention. CA: Cancer J Clin. 2012;62(1):30-67. http://onlinelibrary.wiley.com/doi/10.3322/caac. 20140/full. Accessed June 7, 2012.

5. Health Care Without Harm. Balanced menus challenge. http://www.Healthyfoodinhealthcare.org. Published 2012. Accessed June 7, 2012.

6. Health Care Without Harm. Hydrate for health: a call for healthy beverages in health care. http:// www.noharm.org/lib/downloads/food/Hydrate_For _Health.pdf. Published 2012. Accessed June 7, 2012.

7. Kolasa KM, Thornhill A. NC Prevention Partners' Healthy Hospital Program [Letter to the Editor]. Top Clin Nutr. 2011;26(2):95. doi:10.1097/TIN.Ob013e3182193265.
8. NC Prevention Partners. Healthy eating environment in hospitals. http://www.ncprevention partners.org/dnn/WhatWeDo/Programs/Focuson Hospitals/tabid/73/Default.aspx. Accessed September 8, 2012 .

9. Gaskins S. Healthy hospital food environment: policy \& programs in practice. Paper presented at: CDC Weight of Nation Conference; Washington, DC. http://hdl.handle_netxxx2012. Accessed August 18, 2012.

10. Winner's Circle. Healthy Dining Program. http://www.ncpreventionpartners.org/dnn/WhatWe Do/Programs/WinnersCircle/tabid/76/Default.aspx. Accessed June 7, 2012.

11. US Department of Agriculture. 2010 Dietary Guidelines for Americans. http://www. cnpp.usda.gov/dietaryguidelines.htm. Published January 2011. Accessed June 7, 2012.

12. Schwartz J, Riis J, Elbel B, et al. Inviting consumers to downsize fast-food portions significantly reduces calorie consumption. Health Aff. 2012;31(2):399407.

13. US Food and Drug Administration. New menu and vending machines labeling requirements. http://www.fda.gov/food/labelingnutrition/ucm 21 7762.htm. Published 2011. Accessed June 7, 2012.

14. Gaskins S, Kolasa KM, Bucher C. Healthy Food Environment. Vendor Toolkit. Event Planner Toolkit. Guidelines for Proving Healthy Foods and Beverages at Company Sponsored Events. Greenville NC: Vidant Health. http://hdl.handle.net/10342/3924. Accessed September 8, 2012.

15. NC Prevention Partners. WorkHealthy America. http://www.ncpreventionpartners.org/dnn/Work 
HealthyAmerica/FrequentlyAskedQuestions/tabid/ 206/Default.aspx. Accessed September 8, 2012.

16. Center for Disease Control and Prevention. Improving hospital food and beverage environments. Healthy Hosp Pract Pract Ser (P2P). 2011;(3). http://www.cdc.gov/nccdphp/dnpao/hwi/down loads/p2p/P2P_Food_Issue3.pdf. Accessed June 7, 2012.

17. CRT (Center of Excellence for Training and Research Translation), University of North Carolina Chapel Hill Center for Health Promotion and Disease Prevention. Healthy food environments pricing incentives. http://www.center-trt.org/downloads/obesity_ prevention/interventions/hfe/NCPP_HFE_Template. pdf. Published 2010. Accessed June 7, 2012.

18. Bleich SN, Pollock KM. The public's understanding of daily caloric recommendations and their perceptions of calorie posting in chain restaurants. $B M C$
Public Health. 2010;10:121. doi:10.1186/1471-245810-121.

19. Dietary Guidelines Alliance. 2010 Dietary Guidelines Alliance Consumer Research. Motivating families to lead a healthier lifestyle in 2011 and beyond. http:// www.sne.org/documents/2010_Dietary_Guidelines _Alliance_Report_FINAL.pdf. 2010. Accessed June 7, 2012.

20. Wiseman A, Boothe A, Reynolds M, et al. Healthy Hospital Choices: Recommendations and Approaches from an Expert Panel. Atlanta, GA: Center for Disease Control and Prevention, Division of Nutrition, Physical Activity and Obesity; 2010. http:// www.cdc.gov/nccdphp/dnpao/hwi/resources/ index.htm. Published 2010. Accessed August 24, 2012.

21. Kolasa KM, Firnhaber GC. 13 tips for surviving the 12-hour shift. Nursing. 2011;41(12):55-60. 